\title{
Impact of Soil Water Stress at Seed Development Stage on Phenology, Fecundity and Seed Dormancy of Avena sterilis ssp. ludoviciana ${ }^{\dagger}$
}

\author{
Mohammad Ali ${ }^{1, *}$, Michael Widderick ${ }^{2}$, Alwyn Williams ${ }^{1}$ and Steve Adkins ${ }^{1}$ \\ 1 School of Agriculture and Food Sciences, The University of Queensland, Gatton 4343, Australia; \\ alwyn.williams@uq.edu.au (A.W.); s.adkins@uq.edu.au (S.A.) \\ 2 Department of Agriculture and Fisheries, Leslie Research Facility, Toowoomba 4350, Australia; \\ michael.widderick@daf.qld.gov.au \\ * Correspondence: m.ali2@uq.net.au; Tel.: +61-7-5460-1321 \\ + Presented at the third International Tropical Agriculture Conference (TROPAG 2019), Brisbane, Australia, \\ 11-13 November 2019.
}

Published: 24 December 2019

\begin{abstract}
Wild oat (Avena sterilis ssp. ludoviciana (Durieu) Nyman) is considered the most difficultto-control winter weed in the northern grain region (NGR) of Australia particularly following the adoption of no-till conservation agriculture and the enhanced reliance on herbicides for weed control. A diversity of survival mechanisms is responsible for its persistence in no-till conservation cropping. Among them long-term, variable seed dormancy is the most important. A number of environmental stresses (for example drought) are known to affect the seed dormancy status. We hypothesized that the increasing frequency of hot and dry period in late winter/early spring season in the NGR might help to mature and shed less dormant wild oat seeds before the wheat crop is harvested. This early shedding of highly germinable seed better aids persistence in no-till conservation cropping systems. Our research showed that soil water stress applied at seed development stage resulted in lower number (16-22\% less) of early maturing (5-20 days earlier) less dormant ( $28 \%$ less) seeds compared with control plants. This observation was made for a number of biotypes either coming from within one location or between locations within the NGR. Thus, the frequent hot and dry period at the time of seed development in the NGR is responsible for production of less dormant Avena sterilis ssp. ludoviciana seeds where no-till conservation cropping is helping to retain these seeds on the top soil. Under favourable germination conditions in the following season these less dormant seeds will immediately be available to re-infest the autumn/winter-sown wheat crop.
\end{abstract}

Keywords: wild oat; soil water stress; seed dormancy; no-till conservation agriculture; winter crop

Author Contributions: All the authors involved in planning, design and execution of the experiment. In addition, all the authors paid their attention to develop this abstract.

Funding: This research was funded by the Grains Research and Development Corporation (project ID 9175899).

Acknowledgments: The University of Queensland and, Grains Research and Development Corporation.

Conflicts of Interest: The authors declare no conflict of interest.

(C) 2019 by the authors. Licensee MDPI, Basel, Switzerland. This article is an open access article distributed under the terms and conditions of the Creative Commons Attribution (CC BY) license (http://creativecommons.org/licenses/by/4.0/). 